\title{
Increase in the Annual Energy Production due to a Retrofit of Vortex Generators on Blades
}

Skrzypinski, Witold Robert; Gaunaa, Mac; Bak, Christian; Brønnum, Niels Fiil; Brink Kruse Olsen, Emil

Publication date:

2015

Document Version

Publisher's PDF, also known as Version of record

Link back to DTU Orbit

Citation (APA):

Skrzypinski, W. R. (Author), Gaunaa, M. (Author), Bak, C. (Author), Brønnum, N. F. (Author), \& Brink Kruse Olsen, E. (Author). (2015). Increase in the Annual Energy Production due to a Retrofit of Vortex Generators on Blades. Sound/Visual production (digital)

\section{General rights}

Copyright and moral rights for the publications made accessible in the public portal are retained by the authors and/or other copyright owners and it is a condition of accessing publications that users recognise and abide by the legal requirements associated with these rights.

- Users may download and print one copy of any publication from the public portal for the purpose of private study or research.

- You may not further distribute the material or use it for any profit-making activity or commercial gain

- You may freely distribute the URL identifying the publication in the public portal 


\section{Increase in the Annual Energy Production due to a Retrofit of Vortex Generators on Blades}

1)Witold Skrzypiński (wisk@dtu.dk), 1)Mac Gaunaa, 1)Christian Bak 2)Niels Fiil Brønnum, 2)Emil Brink Kruse Olsen

1)Technical University of Denmark, Department of Wind Energy Frederiksborgvej 399, 4000 Roskilde, Denmark www.dtu.dk

2)Power Curve ApS

Stationsmestervej 81, 9200 Aalborg, Denmark www.powercurve.dk

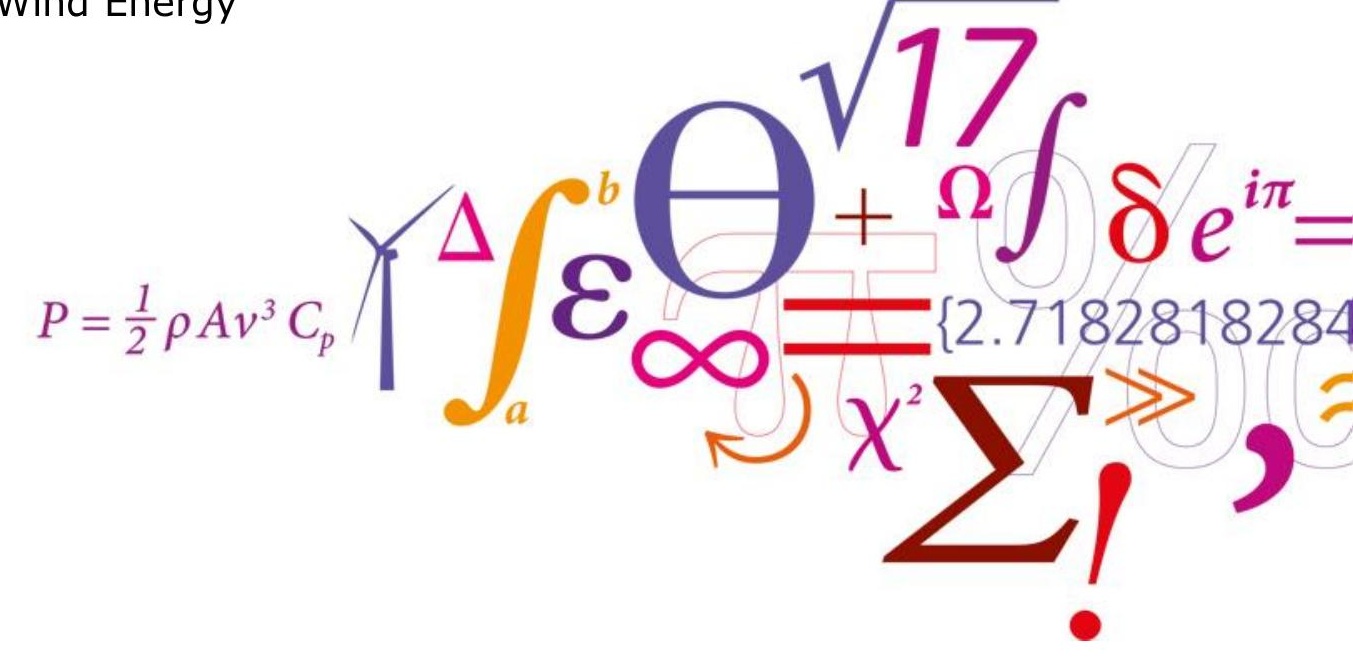

DTU Wind Energy

Department of Wind Energy 


\section{Table of Contents}

- Introduction

- Examples of surface roughness

- Surface roughness - Energy production - VG's

- Methods

- Engineering modelling

- Procedure

o How the engineering model works

- Validation by a full-scale experiment

- Results

- Modelling

- Clean blade surface

- Blades with surface roughness

- Experimental 


\section{Introduction: Examples of surface roughness}

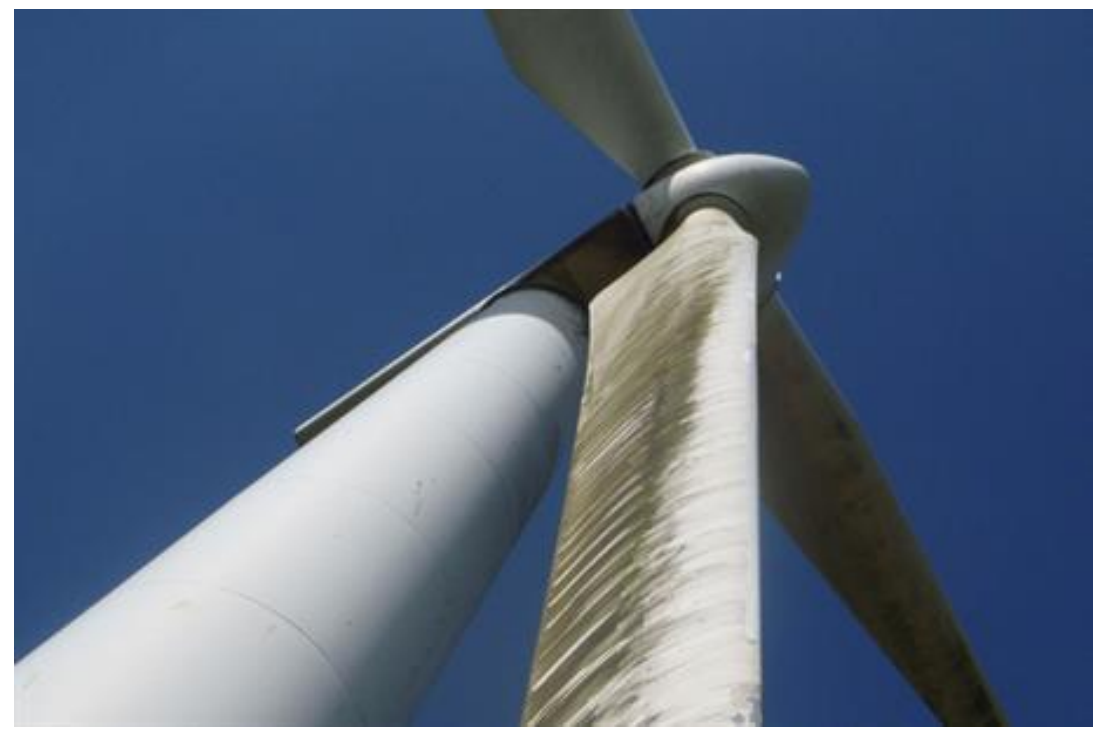

Pic: Renewable Advice

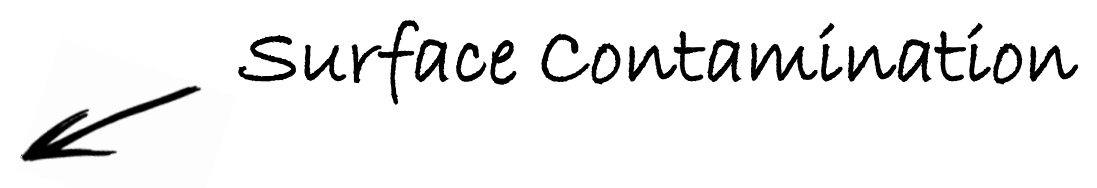

Leading Edge Erosion

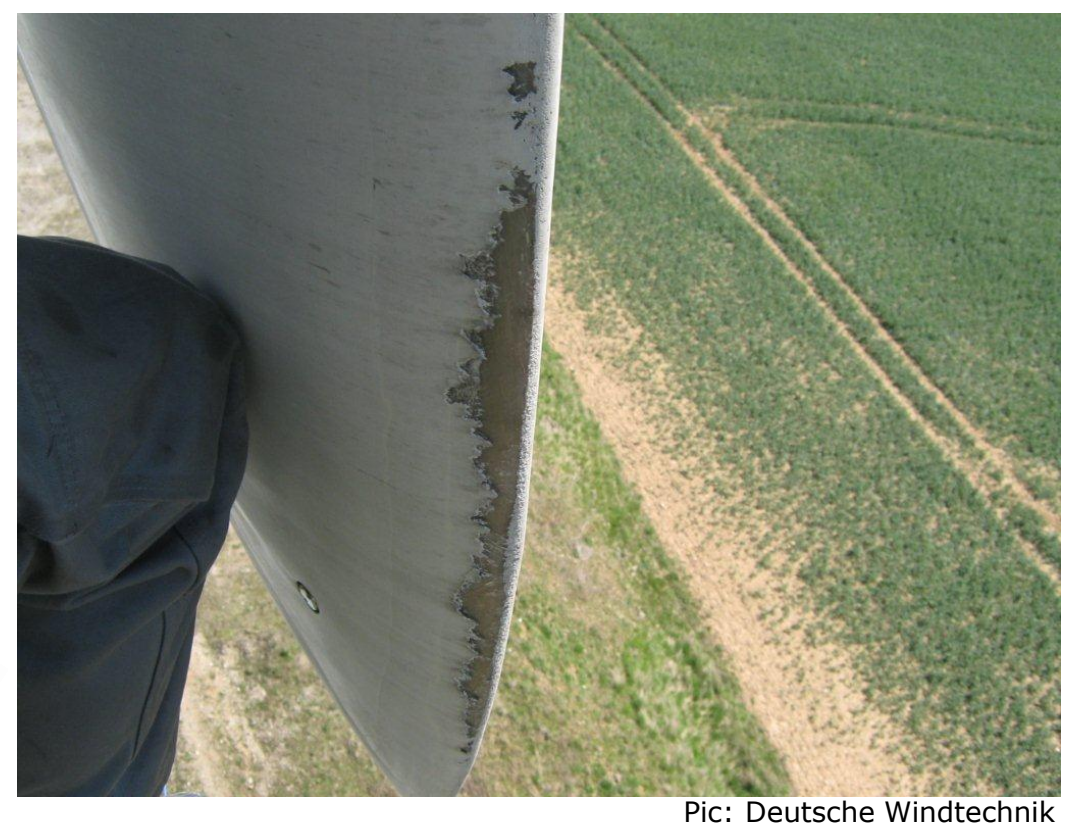


Introduction:

\section{Surface roughness - Energy production - VG's}

\section{So, how it all works?}

Energy Production L/D

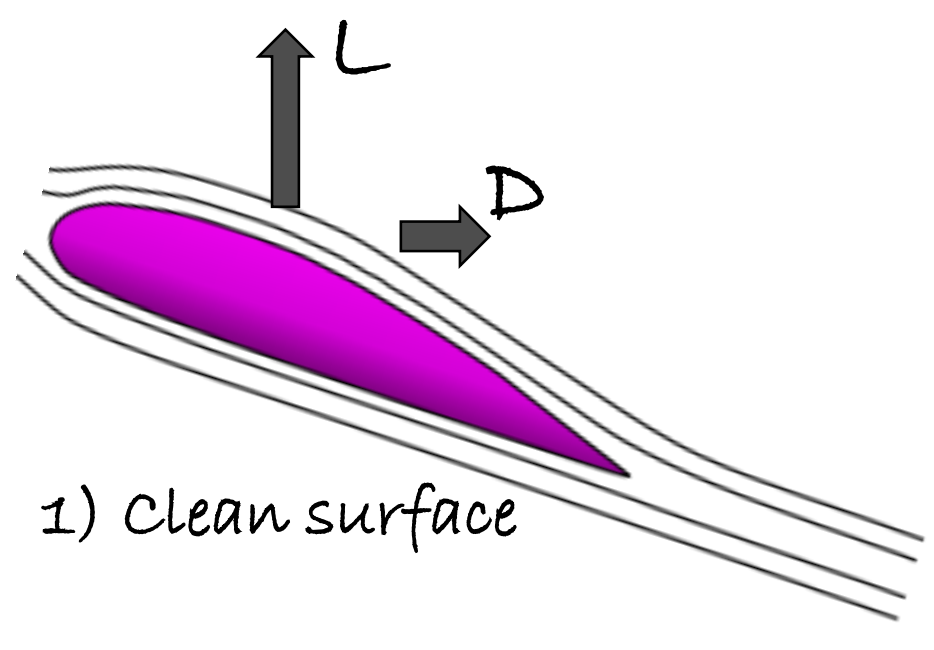

Array of $V G$ 's

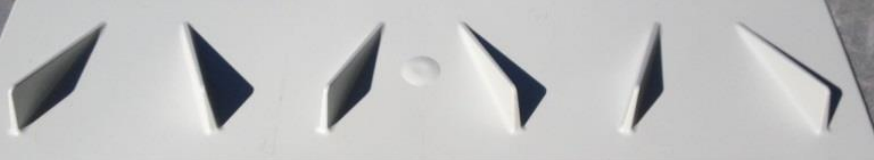

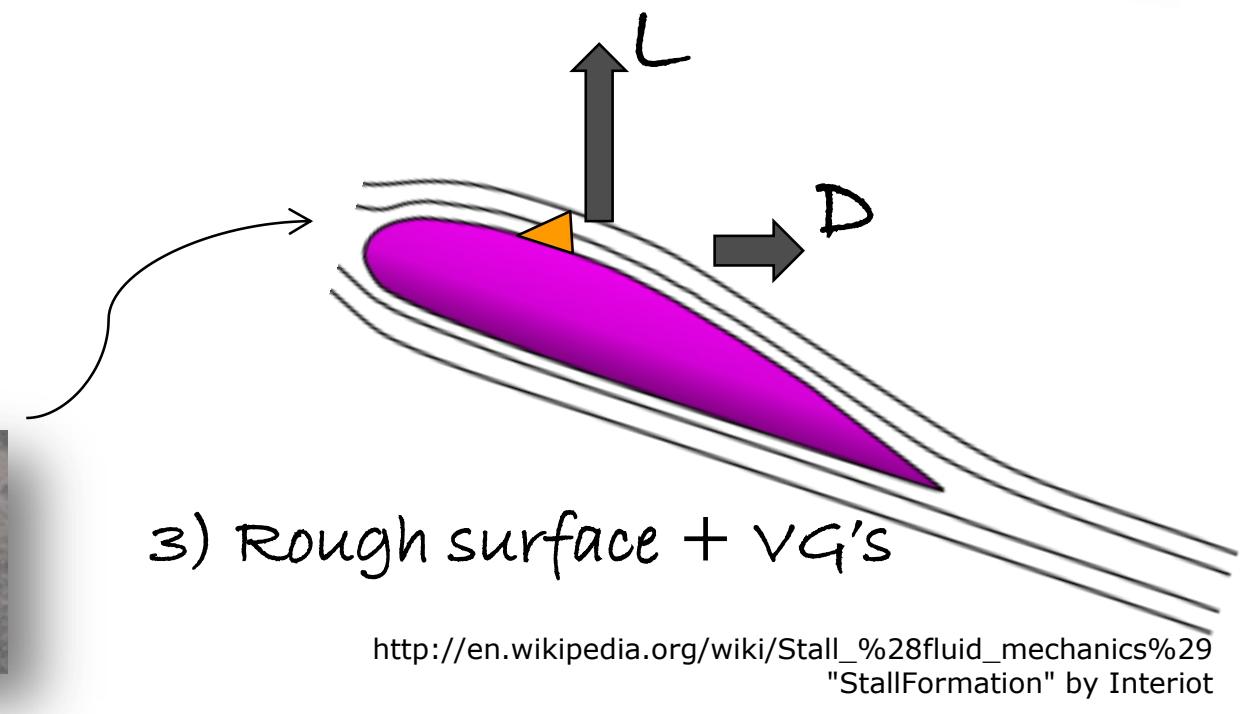




\section{Methods: \\ Engineering modelling - Procedure}

1. Emulate the effect of surface roughness and VG's by modifying the aerodynamic coefficients.

2. Account for the three dimensional effects.

3. Carry out BEM computations with each of the data sets from steps 1-2 along the whole blade span for all the wind speeds in the turbine control scheme.

4. For each discrete radial position determine independently whether it is beneficial to install VG's in the clean and rough case. 


\section{Methods: \\ How the engineering model works}

$\checkmark$ Modelling based on wind tunnel experiments.

$\checkmark$ Lift coefficient as a weighted sum of a fully attached and a fully stalled lift coefficient

$\checkmark$ The weight factor is the separation function. Values between 1 for the fully attached and 0 for the fully stalled flows:

$$
C_{l}(\alpha)=C_{l, a t t}(\alpha) f(\alpha)+C_{l, f s}(\alpha)(1-f(\alpha))
$$

$\checkmark$ Only the separation function altered in the model!

$\checkmark$ Drag coefficient also as a function of the separation function with 3 contributing terms. 


\section{Methods: Engineering model - A figure not as complex as it seems.}

- Comparison of the present VG modelling and wind tunnel results

- Risø-B1-24

- $\operatorname{Re}=1.6 * 1 \mathrm{e} 6$.

- VG's mounted at $x / c=0.2$

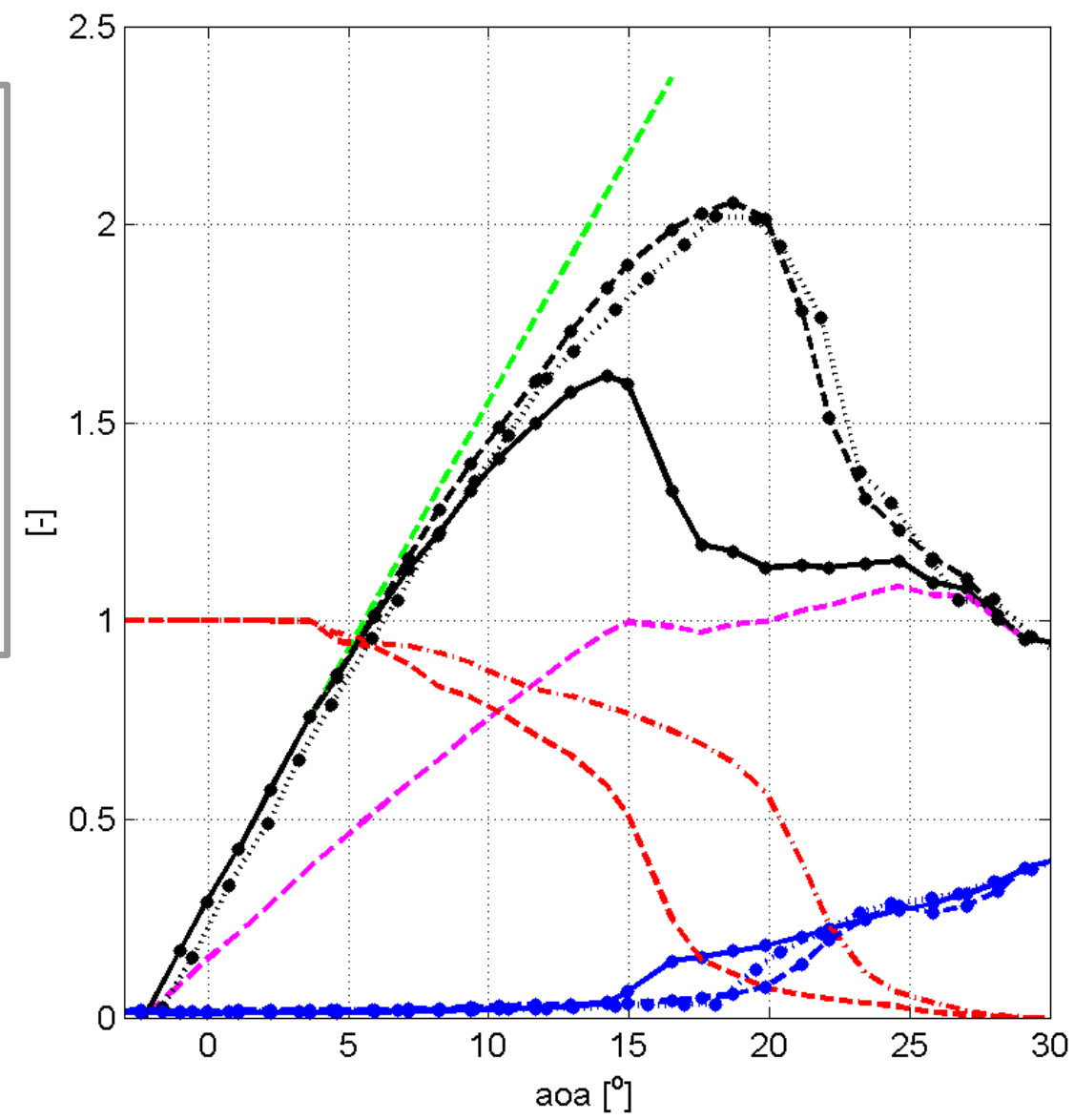




\section{Methods: \\ Full-scale experiment}

1. The power generated by the rotors, wind speed and direction logged for 12 months

2. VG's installed on 3 turbines

3. Data logged for the following 2 months on all 6 turbines

4. The measurement time series from both turbines was divided into temporal bins

5. Power curve was calculated for each bin and each turbine
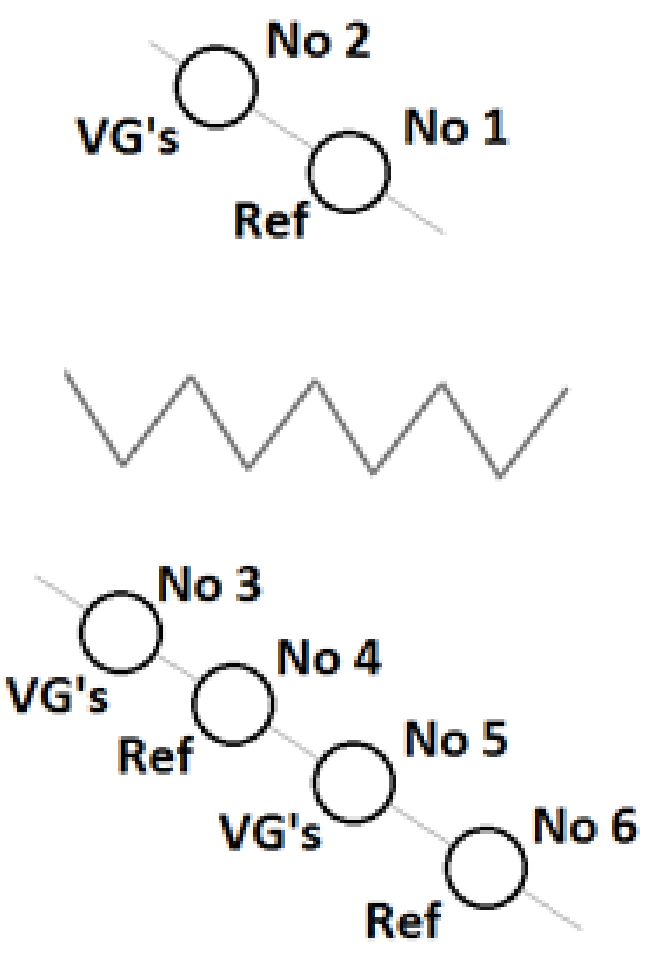


\section{Methods: \\ Full-scale experiment}

6. Assumed a constant statistical wind speed distribution

7. Energy production was calculated for each temporal bin and each turbine

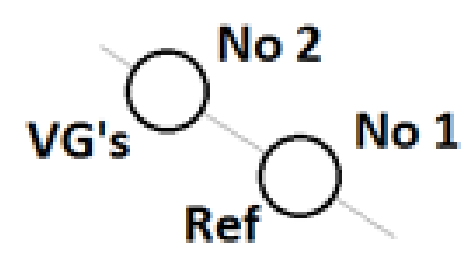

8. The relative difference between those values was calculated as:

$$
E P_{\text {diff }}=\frac{\left(E P_{V G}-E P_{\text {ref }}\right)}{E P_{\text {ref }}}[\%]
$$
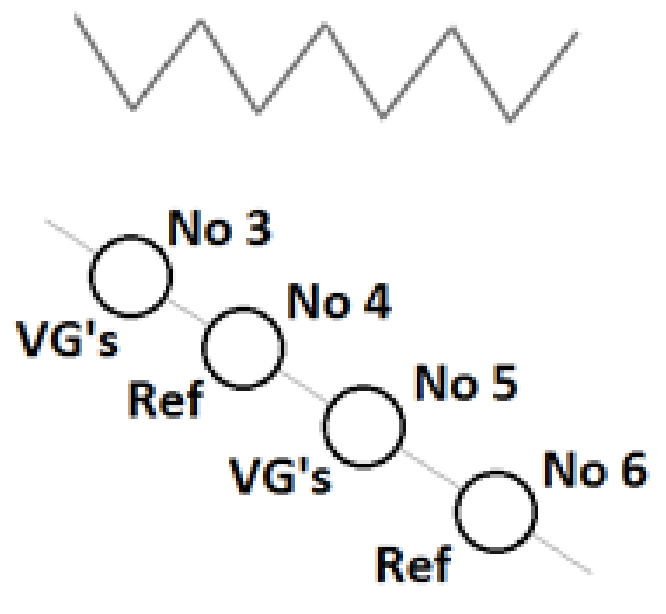


\section{Results:}

\section{Modelling - Clean blades}

Relative increase in the AEP as a function of the radial position until which the VG's were modelled

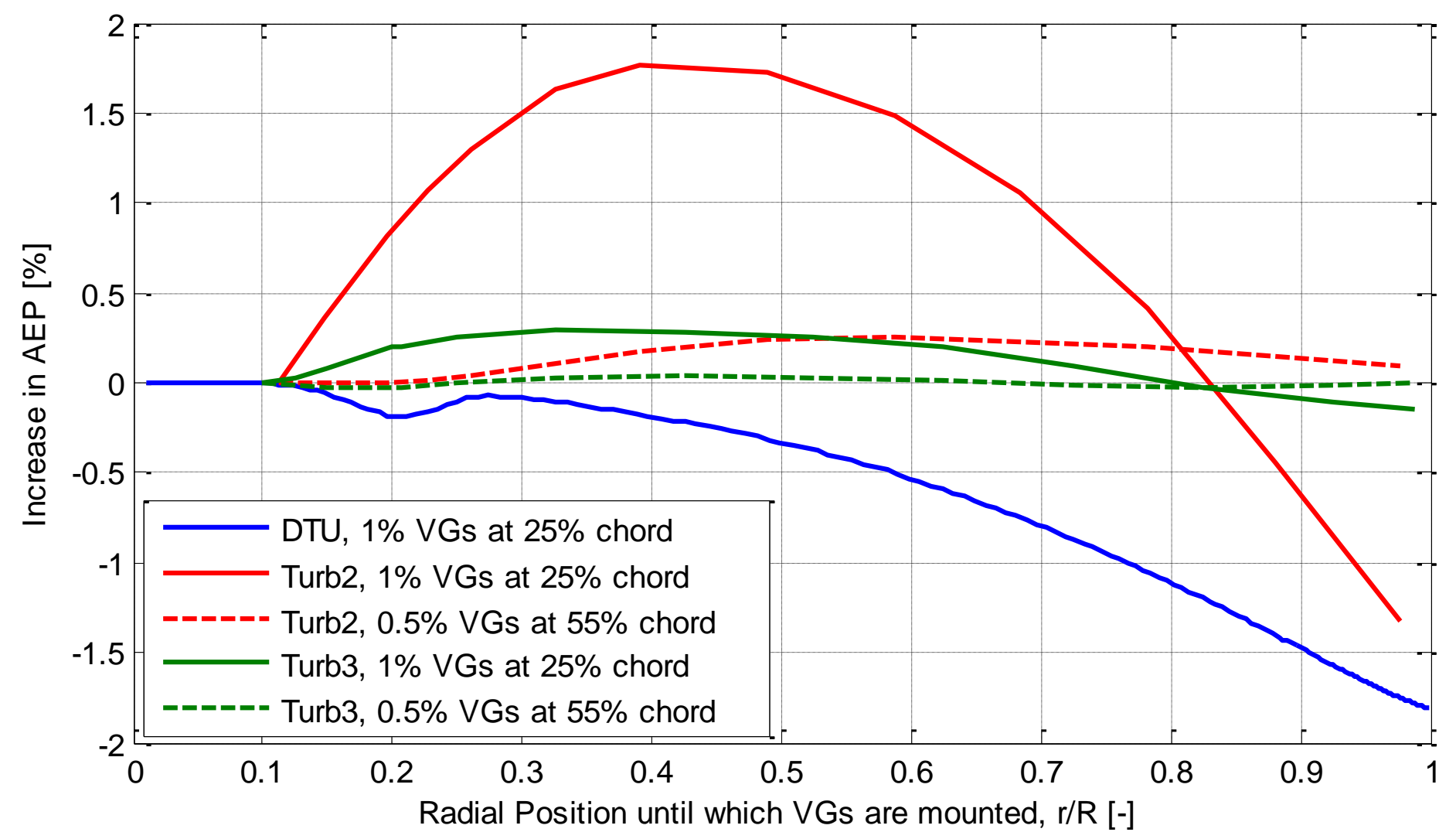




\section{Modelling - Blades with surface roughness}

Relative increase in the AEP as a function of the radial position until which the VG's were modelled

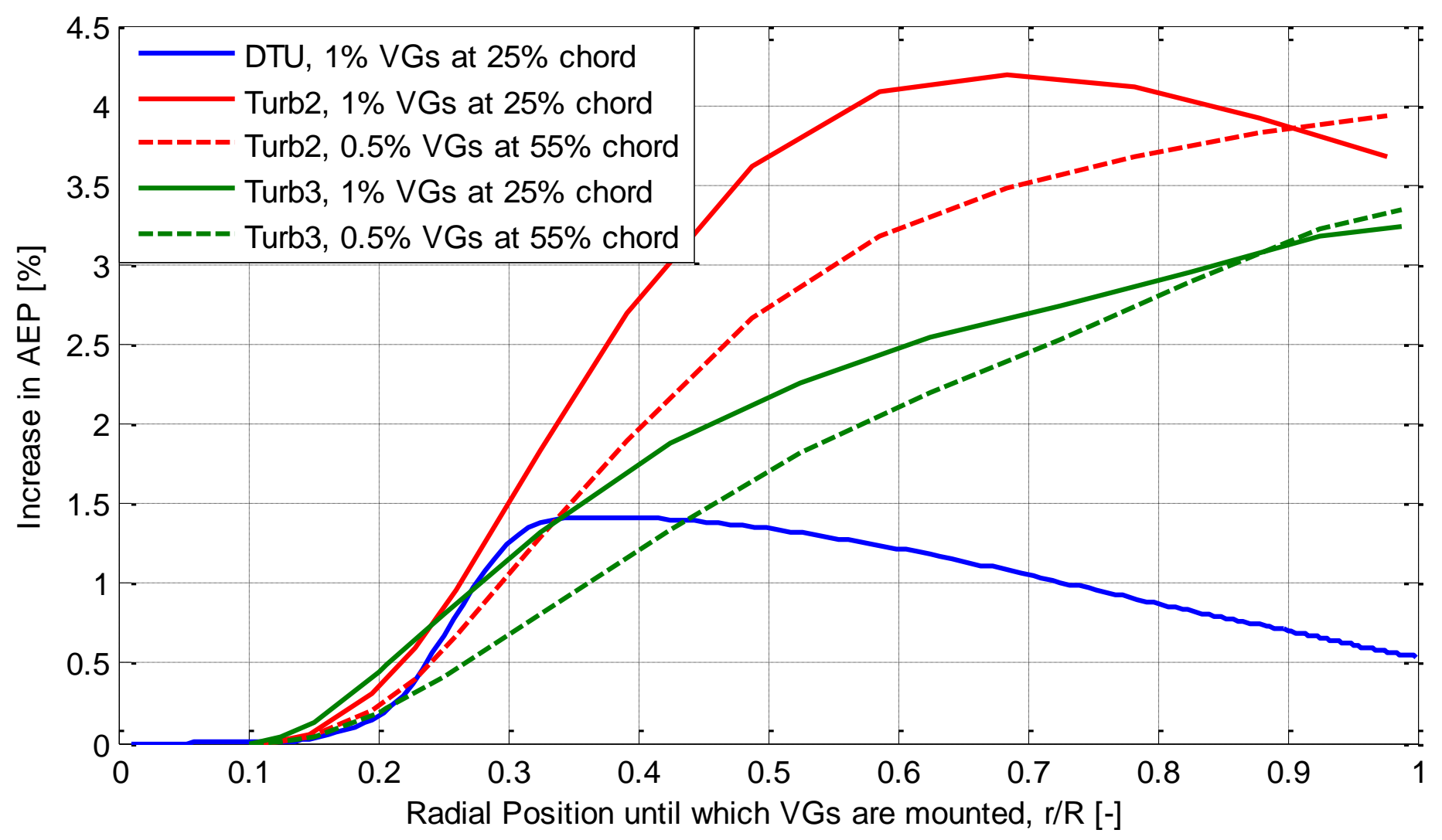




\section{Results:Experimental}

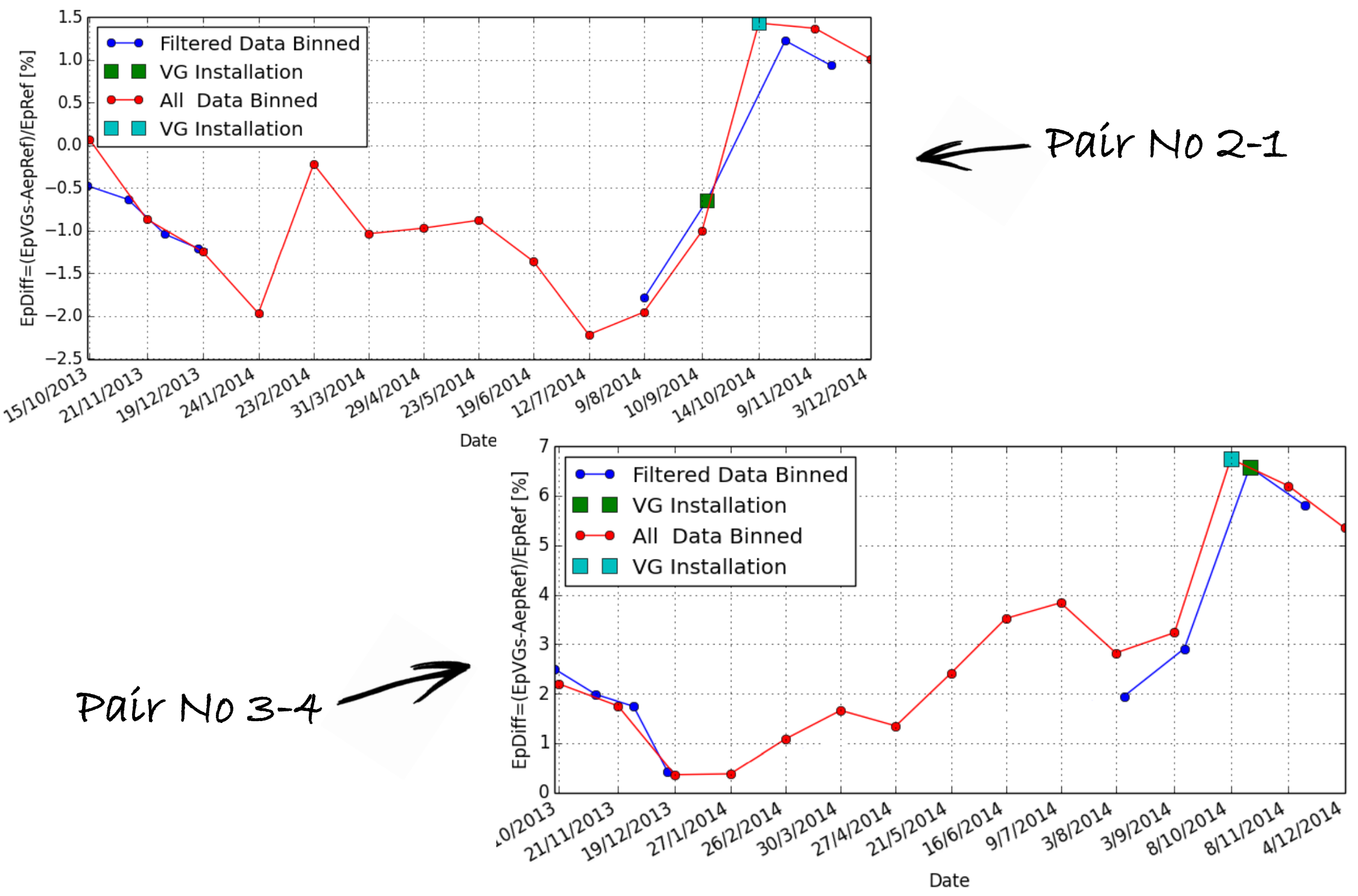




\section{Results:Experimental}

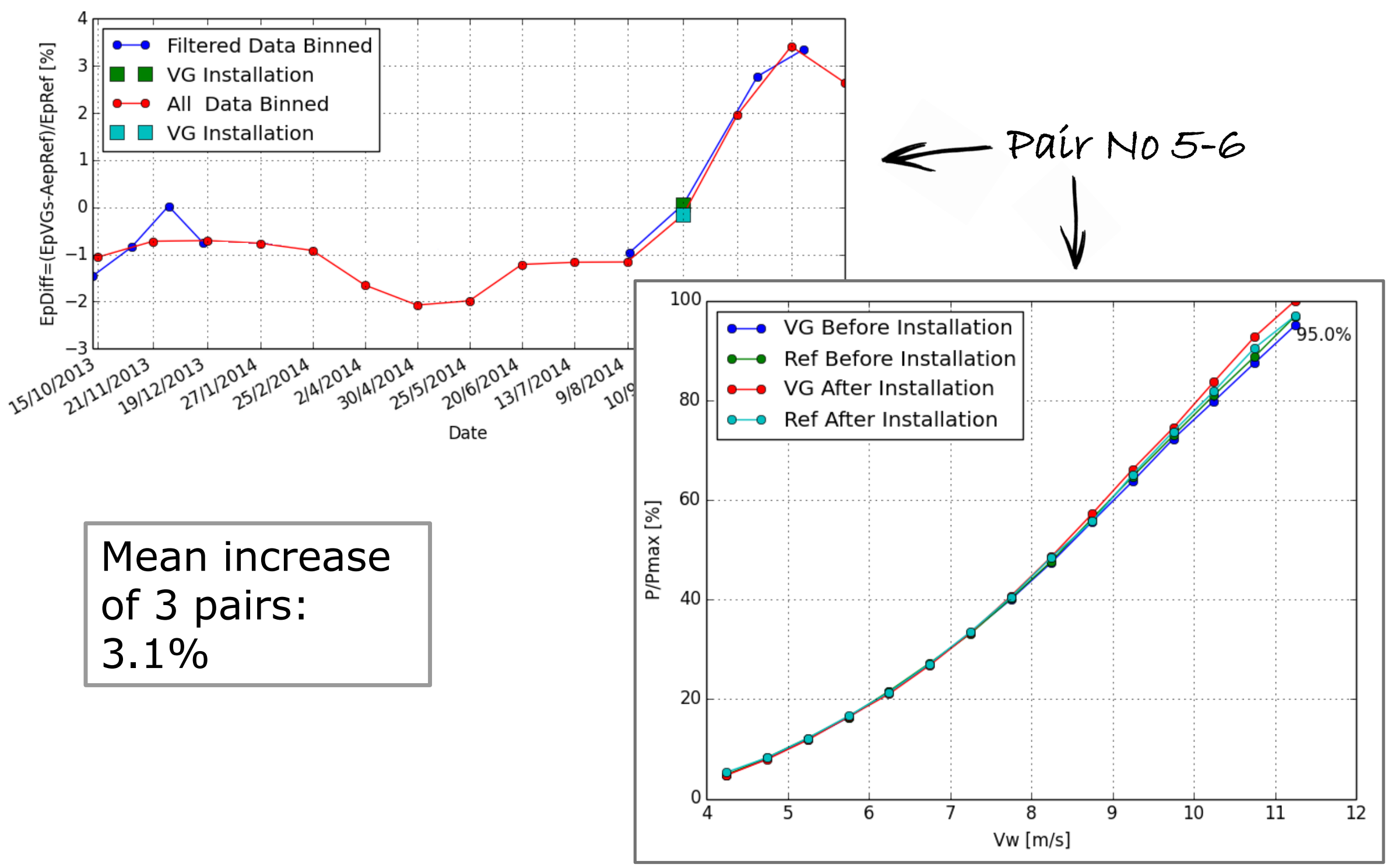




\section{Thank you!}

